\title{
Effect of early intervention in the developmental outcome of hypoxic ischemic encephalopathy infants
}

\author{
N. Meena ${ }^{1}$, Dr V.K. Mohandas kurup ${ }^{2}$, Dr S. Ramesh ${ }^{3}$, Dr. R. Sathyamoorthy ${ }^{4}$ \\ ${ }^{I}$ Assistant Professor in Physiotherapy, Dept. of Physical Medicine \&Rehabilitation, RMMC\&H \\ ${ }^{2}$ Professor, Dept. of Physical Medicine \&Rehabilitation, RMMC\&H \\ ${ }^{3}$ Professor \&Head,Dept of Pediatrics, RMMC\&H \\ ${ }^{4}$ Former HOD of Dept of Statistics, AnnamalaiUniversity, Annamalai Nagar ,Tamilnadu
}

\begin{abstract}
:
Background: Neonatal brain injury due to intrapartum asphyxia is a significant cause of cerebralpalsy, mental retardation, and epilepsy. Despite advances in perinatal care over the pastthree decades, the incidence of cerebral palsy attributed to birth asphyxia has not changed. Indeveloping countries, the incidence of post asphyxiate neurological damage is particularly high.

Objectives: To study the developmental outcomes of hypoxic ischemicencephalopathy infants by early physiotherapy intervention till one year

Methodology: This study had conducted on 48 asphyxiated full term newborn infants who developed HypoxicIschemic Encephalopathy (HIE) admitted in Neonatal Intensive Care Unit (NICU) of Rajah Muthiah Medical College \&hospital. The studied infants have classified on the basis of Sarnat and Sarnat staging of HIE into 3 stages, and they were given early intervention. Denver developmental screening test have administered to infants every four months till one year. The level of achievement of various developmental domains in among various stages of HIE early intervention infants were compared.

Results: We found improvement in the level of achievement of developmental domains in various stages of birth asphyxia infants with a better outcome in stage I HIE infants.

Conclusion: The early interventional program on HIE infants in the neurodevelopmentaloutcome after one year of age investigated in this study was efficacious in infants who participated in thestudy.
\end{abstract}

Keywords: Birth asphyxia, Hypoxic ischemic encephalopathy, Early physiotherapyintervention, Developmental outcome

\section{Introduction}

According to the World Health Organization (WHO), four to nine million cases of newborn asphyxiaoccur each year. ${ }^{1}$ The incidence of birth asphyxia ranges from $0.3 / 1000$ in a Swedish study ${ }^{2}$ to $36.6 / 1000$ live birth infants in an Indian study. ${ }^{3}$ In spite of significant advances in monitoringtechnology, obstetric care and knowledge of foetal and neonatal pathologies, asphyxia remainsa serious condition causing significant mortality and long- term morbidity. ${ }^{4}$ More than a millionnewborns who survive asphyxia at birth develop long-term problems such as cerebral palsy, mental retardation,speaking, hearing, visual and learning disabilities. ${ }^{1}$ An earlyintervention (EI) could improve neuro-developmental outcomes in survivors of birth asphyxia.Early detection of infants at high risk is of paramount importance, to assess their developmentalstatus and for planning intervention so that secondary problems can be avoided.

Early intervention (EI) consists of providing continuous multidisciplinary services to infants from birth throughoutthe first year of life. It means interventional therapy specified for babies at-risk for developmentaldelay and periodic developmental assessment of motor, cognitive function, language/adaptivefunctioning ${ }^{5}$. EI promotes child health, minimize developmental delays, cures existing disabilities, prevents functional deterioration, and promotes parent- child interaction ${ }^{5}$.

Little work had done on neurodevelopmental outcomes of babies surviving birth asphyxia in developing countries. ${ }^{6}$ Very few studies had done on the outcome of asphyxiated infants. Various studies on theoutcome of neonatal asphyxia have documented, but high-risk follow up programs specifically forphysiotherapists have not been widely reported or studied. ${ }^{7}$ No physiotherapy generated studies on the neurodevelopmental outcome and/or follow up of asphyxiated infants could be found except the study by Robertson and Finer. ${ }^{8}$ Involvement of physiotherapist in theimmediate and long-term assessment, and follow up of the asphyxiated infant remains largelyunexplored. By reviewing various studies, there is no uniformity exists regarding inclusion criteria, methods, assessors or the period of follow up. ${ }^{9-12}$ This resultantly makes it extremely difficult tocompare the outcomes of these studies with each other. Thus, we employed to study the effects ofEI in the neurodevelopment of Birth asphyxia infants followed till their one year of age. 
The goal of this study is to measure the effect of EI program in various stages of HIE infants. Thehypothesis is that HIE infants under EI will not achieve the developmental domains equal to normal infants. The clinical staging of Sarnat and Sarnat has been widely used as a staging examination to estimate the severity of the hypoxic ischaemic insult in infants. DDST comprising of gross motor, fine motor, personal social and language domains have used prospectively to evaluate the effects of EI on theirneurodevelopment during follow-up in the first year of life.

\section{Methods}

Samples: Asphyxiated full term newborn infants who developed HIE admitted in NICU ofRMMC\&Hhas recruited for the study (Experimentalgroup). Fifty full term normal newborninfants served as the control group. Sarnat and Sarnat criteria for clinical encephalopathy have used to infants of 36 or more weeks of gestation to determine the degree of neuronal injurybased on the infant's symptoms.

The studied infants have classified on the basis of Sarnat and Sarnat staging of HIE into the following 3 groups ; Group I ( stage I HIE) included 8 infants, Group II ( stage II HIE) included 32 infants and Group III ( stage III HIE) included 9infants. Fifty healthy full term newborn infants' age and weight matched served as control.

Inclusion criteria: For study group, term newborn infants completed 37 week of gestation withApgar score $<7$ at $5 \mathrm{~min}$, and clinical signs of asphyxia have included. For the control group, termnewborn infants with no maternal illness, Apgar score $>7$ at $5 \mathrm{~min}$, and uneventful clinical courseduring the first 3 days of life have included.

Exclusion criteria: Infants with Gestational age $<37$, perinatalinfection, congenital anomalies or metabolic disorders and those who did not complete thecourse of the follow up had excluded.

\section{Early Intervention}

Early Intervention has initiated for high risk infants right from the neonatal period after thebabies became stable. Early intervention applied remarkably to HIE infants in order to arousetheir actions and feelings ultimately giving them a normal experience of development throughinteraction with the mother and environment. ${ }^{5}$ Individually adjusted program had described to theparents (especially to the mother) who have trained and received written programs elaboratedfor their infants. This program contains intensive schedules to develop elementary sensorimotorpatterns. Also individualized care plans, centered on the infant behavioral organization; mother child interaction and extending to vision hearing feeding and vocalization. Stimulation had given for at least one hour a day according to the infant feeding and sleep time schedule. Infants had reviewed every month. It have emphasized that aside from the training programs the infant requires the affection and care of the family members. Infants assigned tostudy group received regular early interventional therapy.

\section{Denver developmental screening test (DDST)}

The Denver developmental screening test is an easy clinically useful tool for the early detection ofinfants with developmental delay ${ }^{13}$. The test comprised of four domains namely gross motor finemotor/adaptive language and personal social. The level of achievement has scored as advanced, ok/pass, caution and fails depending on the age line.

\section{Data Analyses}

It was proposed to examine whether the average level of various developmental domains achievement differ significantly between the 3 stages of BA infants. To examine the null hypothesis $\mathrm{H}_{\mathrm{o}}$ : The average scores of various developmental domains achievements do not differ significantly between the infants belonging to the 3 stages, due to the given early intervention. For this purpose the non-parametric test namely Kruskal-wallis one way ranked analysis of variance procedure ${ }^{14,15}$ was adopted.

\section{Results}

Birth Asphyxia infants were categorized in to 3 stages namely stage I, Stage II and Stage III. Early intervention was given to these infants from birth. The level of achievement in various developmental domains of these EI Infants was assessed after $4^{\text {th }} 8^{\text {th }}$ and $12^{\text {th }}$ month.

According to Sarnat and Sarnat staging of HIE, The study included 8 newborn infants with stage I HIE ( group I), 32 newborn infants with stageII HIE( group II) and 9 newborn infants with stage III HIE( group III); 
and 50 healthy full termnewborn infants as control. All study infants were age and weight matched with no statisticaldifference regarding their gestational age and the birth weight.

The level of achievement in various domains of these EI Infants was assessed after $4^{\text {th }} 8^{\text {th }}$ and $12^{\text {th }}$ months. It was proposed to examine whether the average level of various domains achievement differ significantly between the 3 stages of BA infants. To examine the null hypothesis Ho: The average scores of various domains achievements do not differ significantly between the infants belonging to the 3 stages, due to the given early intervention. For this purpose the non-parametric test namely Kruskal-wallis one way ranked analysis of variance procedure was adopted.The mean value of the level of achievement in gross motor, fine motor, personal social, language developmental domain at $4^{\text {th }} 8^{\text {th }}$ and $12^{\text {th }}$ month of various stages of HIE infants are given in table 1 .

Table-1: Mean values of all domains achievement at $4^{\text {th }} 8^{\text {th }}$ and $12^{\text {th }}$ month Gross motor domain

\begin{tabular}{|c|c|c|c|}
\hline \multirow{2}{*}{$\begin{array}{c}\text { Stages of } \\
\text { BA }\end{array}$} & \multicolumn{3}{|c|}{ Mean values } \\
\cline { 2 - 4 } & $4^{\text {th }}$ month & $8^{\text {th }}$ month & $12^{\text {th }}$ month \\
\hline I & 3.000 & 3.512 & 3.875 \\
\hline II & 2.069 & 2.806 & 3.548 \\
\hline III & 1.000 & 1.11 & 1.33 \\
\hline
\end{tabular}

Fine motor domain

\begin{tabular}{|c|c|c|c|}
\hline \multirow{2}{*}{$\begin{array}{c}\text { Stages of } \\
\text { BA }\end{array}$} & \multicolumn{3}{|c|}{ Mean values } \\
\cline { 2 - 4 } & $4^{\text {th }}$ month & $8^{\text {th }}$ month & $12^{\text {th }}$ month \\
\hline I & 3.000 & 3.509 & 3.75 \\
\hline II & 2.054 & 2.774 & 3.451 \\
\hline III & 1.000 & 1.000 & 1.222 \\
\hline
\end{tabular}

\section{Personal social domain}

\begin{tabular}{|c|c|c|c|}
\hline \multirow{2}{*}{$\begin{array}{c}\text { Stages of } \\
\text { BA }\end{array}$} & \multicolumn{3}{|c|}{ Mean values } \\
\cline { 2 - 4 } & $4^{\text {th }}$ month & $8^{\text {th }}$ month & $12^{\text {th }}$ month \\
\hline I & 3.000 & 3.500 & 3.62 \\
\hline II & 2.064 & 2.709 & 3.322 \\
\hline III & 1.000 & 1.000 & 1.141 \\
\hline
\end{tabular}

Language domain

\begin{tabular}{|c|c|c|c|}
\hline \multirow{2}{*}{$\begin{array}{c}\text { Stages } \\
\text { of BA }\end{array}$} & \multicolumn{3}{|c|}{ Mean values } \\
\cline { 2 - 4 } & $4^{\text {th }}$ month & $8^{\text {th }}$ month & $12^{\text {th }}$ month \\
\hline I & 3.000 & 3.500 & 3.821 \\
\hline II & 2.044 & 2.700 & 3.129 \\
\hline III & 1.000 & 1.000 & 1.060 \\
\hline
\end{tabular}

From the table, there is a significant difference in the average level of achievement of developmental domains in various stages of HIE after $4^{\text {th }} 8^{\text {th }}$ and $12^{\text {th }}$ months of intervention. It is also seen that for the BA infants under stage I, the average level of improvement is more when compared to other stages of BA infants. Therefore, for the infants with BA the EI is able to give greater achievement in language domain in stage I BA and to some extent in stage II BA when compared to stage III BA infants.

\section{Discussion}

We studied the effects of intensive EI in selected sample of HIE infants from neonatal period to 12 months of age. We found a better performance in the EI infant group and narrowing in the developmental outcome by one year in comparison with that of normal infants. The study suggests a positive effect of EI in the developmental outcome of BA infants.

Perinatal asphyxia and resulting hypoxic ischemic encephalopathy (HIE) occur in 1 to 3 per 1000births in the United States. Higher rates occur in developing countries with limited diagnostic andinterventional resources. ${ }^{16}$ The survivors will have long- term neurodevelopmental sequelae. ${ }^{17}$ Hypoxicischemic encephalopathy is the primary cause of $15 \%$ to $28 \%$ of cerebral palsy among children. Perinatal asphyxia progresses to HIE based on the degree of brain injury and resulting clinical presentation. ${ }^{18}$ It has estimated that an equal or larger proportion of survivors suffer brain damage resulting inmental retardation and cerebral palsy.

At neonatal follow-up clinics, a large proportion of infants with developmental delays or cerebral palsy retrospectively have a history of birth asphyxia. ${ }^{19}$ The effects of asphyxia on long-term developmental outcome are greater in term infants which concurs the study. ${ }^{20}$ 
Early intervention programs (EIP) improvethe neurodevelopmentaloutcomes in survivors of birth asphyxia. By early intervention the level of achievement of all developmental domains has improved. In addition, the present study revealed gestational age particularly post-term gestation significantly associated with HIE. The small for gestational age (SGA) infants showed a slightly increased risk, but this difference was not statistically significant. In the present study Apgar scores observed at 5-minute Apgar scores were significantly lower in HIE infants than normal infants. One can anticipate that a 5-minute Apgar score of 3 or less is highly indicative of severe perinatal asphyxia and a strongly predictive risk for HIE.

It had emphasized that, the importance of neurodevelopmental assessment and follow up of asphyxiated infants should include neurological as well as developmental testing. The role of the neurodevelopmental assessment is to assess the integrity of the musculoskeletal system, searching for any abnormality in movement. For the purpose of this study, both neurological and developmental assessment have included in the data form.

The frequently observed major and minor neurodevelopmental impairments in asphyxiated infants is motor impairments, visual impairments, hearing impairments, cognitive and learning impairments. ${ }^{21}$ Any infant who suffered a significant asphyxia episode should be monitored closely fordevelopmental difficulties after hospital discharge. The aim of regular monitoring is to identify, asearly as possible, presence of developmental delays and the signs of future disability ensuringthe provision of appropriate services and support to the infant and their families. Follow up of allmoderately to severely asphyxiated infants have suggested, neurodevelopmental screening on itsown had viewed sensitive in identifying infants in need of intervention and early intervene them at the earliest.

\section{Conclusion}

The early intervention on HIE infants after one year of age in the neurodevelopmental outcome investigated in this study was efficacious in infants who participated in the study.

\section{References}

[1] World Health Organization, Facts and figures on Birth Ashyxia; 2005

[2] Thorberg E, Thiringer K, Odeback A, Milsom I. Birth asphyxia: incidence, clinical course and outcome in a Swedish population. ActaPaediatr 1995;84: 927-32.

[3] Chandra S, Ramji S, Thirupuram S. Perinatal asphyxia: multivariate analysis of risk factors in hospital births.IndianPediatr 1997; 34: 206-12.

[4] Raju, T.N.K. Hypoxic-Ischaemic Encephalopathy. EMedicine specialties, 2003; pp. 1-3, 5, 6, 8

[5] M.K.C Nair, Neurodevelopmental follow up- "Module on Early Stimulation," Editors TanmayR.Amladi, 2004

[6] Halloran DR, McClure E, Chakraborty H, Chomba E, Wright LL and Carlo WA, BA survivors in a developing country. J Perinatol $2009 ; 29: 243-249$

[7] Lekskulchai, R. \& Cole, J. Effect of a developmental program on motor performance in infants born preterm. Aus Jour of Physiotherapy 2001; 47:169 -170

[8] Finer NN, Robertson CM, Richards RT, PinnellLE,Peters KL. HIE in term neonates: perinatal factors and outcome. J Pediatr 1981; 98:112-117.

[9] Thornberg, E., Thiringer, K., Odeback, A. \&Milsom, I. Birth asphyxia:incidence, clinical course and outcome in a Swedish population. ActaPaedi1995; 84: 927 -932

[10] Thompson, C.M., Putterman, A.S., Linley, L.L., Hann, F.M., van der Elst, C.W.,Molteno, C.D. \& Malan, A.F. The value of a scoring system for HIE in prediciting neurodevelopmental outcome. ActaPaediatrica1997 ;86: 757-761

[11] Robertson, C. \& Finer, N. Term infants with HIE: outcome at 3.5 years. Developmental Medi\& Child Neurology 1985 ; (27): 473484

[12] Hull, J. \& Dodd, K.L. Falling incidence of HIE in term infants. British journal of Obstetrics and Gynaecology1992 ; 99. P: $386-391$

[13] Denver Developmental Materials, Inc, PO Box6919, Denver, Colorado 80206/9019; (303) 355-4729

[14] William R.Dillon Mathew Gold Stein - Multivariate Analysis - Methods and applications - 1984.

[15] Sindney Siegel McGraw - HILL - Non parametric statistics for the behavioral sciences - 1956.

[16] Halloran DR, McClure E, Chakraborty H, Chomba E, Wright LL, Carlo WA. Birth asphyxia survivors in a developing country. J Perinatol2009; 29(3): 243-249.

[17] Al-Macki N, Miller SP, Hall N, Shevell M. The spectrum of abnormal neurologic outcomes subsequent to term intrapartum asphyxia. PediatrNeurol2009; 41(6): 399-405.

[18] Pierrat V, Haouari N, Liska A, Thomas D, Subtil D, Truffert P. Prevalence, causes and outcome at 2 years of age of newborn encephalopathy. Population based study. Arch Dis Child - Fetal Neonat Ed 2005; 90(3):257

[19] Mokhachane, M., Velaphi, S., Beck-Arnold, E., Mphalele, S. \&Okudu, G.The incidence of perinatal asphyxia at the C. H. Baragwanath Hospital, can it be Reduced, 2002; p:1.

[20] Abbasi KA, Mirani PH, Parsram, Sarwar A. Causes, clinical features and outcome of 150 newborns with birth asphyxia at Larkana Hospital. Pakistan J Pathol 1997; 8: 121-25.

[21] Simon, N.P. Long-term neurodevelopmental outcome of asphyxiated newborns. Clinics in Perinatology 1999; 26(3) 767-776 